\title{
How Can Gender Discrimination Explain Fertility Behaviors and Family-friendly Policies?
}

\author{
Magali Recoules*
}

July 2010

\begin{abstract}
This paper focuses on the interaction between gender discrimination and household decisions. It develops a model with endogenous fertility, endogenous labor supply and endogenous size of government spending. Family policies which concern childcare services, are assumed to reduce the time that parents spend on their children. The model shows that gender discrimination may explain differences in household decisions between countries. The solution shows a U-shaped relationship between fertility and gender discrimination if the quality of childcare services are sufficiently high. In the decreasing part of this U-shaped curve, a decrease in the discrimination level implies a related increase in fertility, women's participation in the labor force and in family-friendly policies.
\end{abstract}

Keywords: Gender discrimination, Fertility, Labor supply, Public policies

JEL Classification: D13, H31, J13, J71

*Paris School of Economics - University of Paris 1 Panthéon-Sorbonne, CES 106-112 boulevard de l'hôpital 75647 Paris cedex 13, magali.recoules@univ-paris1.fr. 


\section{Introduction}

Since the middle of the 1980s empirical studies have shown an inversion of the crosscountry correlation between the female labor supply and the fertility rates in OECD countries (Ahn \& Mira, 2002). Now, the countries exhibiting the lowest levels of female employment are also those that have low fertility rates. And the countries that are characterized by the highest levels of female employment are also those that have high fertility rates. Some authors propose to explain these features by changes in institutional context, such as labor market arrangements and family-friendly policies (Adesrà, 2004; Brewster \& Rindfuss, 2000). ${ }^{1}$ Family-friendly policies differ considerably from country to country both in their type and their extent. In particular, the countries with both high fertility and female employment are also those that have high state intervention concerning family (Del Boca \& Locatelli, 2007).

How can such differences in household decisions as family-friendly policies, fertility and the female labor supply, be explained? This chapter proposes an explanation based on gender discrimination in the labor market. In particular, this chapter studies the way in which gender discrimination affects the related decisions on fertility, the female labor supply and family policies. Labor market discrimination, by reducing the wage of women, influences household decisions through three direct effects. A rise in gender discrimination leads to both an increase in the specialization of women in household activities and to a decrease in the child-rearing opportunity cost in terms of earnings, as well as a decrease in the total household income. The two former effects play in favor of fertility, while the latter tends to reduce it. Moreover, the joint decrease in household income and the opportunity cost of children tends to reduce the willingness to pay for family-friendly policies which finance childcare services. By combining the effects of discrimination through shifts in female wage and in size of public spending, the model provides a U-shaped relationship between fertility and gender discrimination. If the discrimination is not too high, a drop in gender discrimination leads to a related rise in fertility, the female labor supply and in family policies.

This chapter is based on three crucial assumptions. First, that there is gender discrimination in the labor market that leads to a gender wage gap. Thus for the same skills and working time, women receive a lower wage than men because of gender discrimination. In the literature, gender discrimination partly accounts for the gender wage gap (Becker, 1957; Aigner \& Cain, 1977; Coate \& Loury, 1993; Francois, 1998) and thus for the differences in child-rearing opportunity cost between spouses. Secondly, there is a childrearing technology which relates the time cost of rearing children with public policies. And the efficiency of this technology plays an important role in fertility decisions. The cost of

1. Jaumotte (2003) studies the factors determining the female labor supply in OECD countries and finds that public spending in child care stimulates female employment. D'Addio and Mira d'Ercole (2005) study the determinants of fertility and find that OECD countries characterized by wider childcare availability and lower direct costs of children, have higher total fertility rates. 
having children is affected by discrimination through two ways, shifts in female wage and in the size of family-friendly policies. ${ }^{2}$ Finally, family-friendly policies are assumed to be endogenously determined through a vote of agents.

The economy is composed of men and women organized as couples. Each man and woman having the same preferences, all households are identical. Household decisions are determined through a two-stage decision process. The first stage refers to the size of public spending, more specifically the taxation level which is determined through a vote of agents. Each member of the couple singly chooses the taxation level that maximizes his or her indirect utility. If men and women display different preferences there is no consensus concerning the expected tax rate within the society as individuals of each gender groups have different preferred tax rates. In this context, I use as in the literature a political process represented as a probabilistic voting model in the first stage (Lindbeck \& Weibull, 1987; Persson \& Tabellini, 2000). The second stage refers to fertility, labor supply and individual consumption choices. These decisions are taken cooperatively within the couple and result from the maximization of a weighted sum of spouses utilities under household budget constraint, the weightings being the bargaining power of each partner.

The model shows that different intensities of gender discrimination may explain the differences in household decisions across countries. Gender discrimination, by acting on the female wage, modifies the allocation of tasks within the household and implies a specialization of gender roles. An increase in gender discrimination discourages the participation of women in the labor market which implies a decrease in the childrearing opportunity cost in terms of earnings as well as a reduction in the household income. By staying at home for longer, women's demand for public services decreases and agents vote for a lower tax rate that boosts the childrearing opportunity cost in terms of time. So a rise in discrimination has ambiguous effects on the overall cost of having children. If the efficiency in childrearing technology is sufficiently high, the solution of the model shows a U-shaped relationship between fertility and gender discrimination. For a low level of discrimination, an increase in discrimination rises the overall cost of having children and puts off the childbearing decision as the opportunity cost in terms of earnings is dominated by the other effects. Beyond a discrimination threshold the opportunity cost in terms of earnings outweighs the other effects and reduces thereby the overall cost of having children. In this case, an increase in discrimination pushes households to have more children. Hence in the first part of the U-shaped curve, a drop in the discrimination level implies a related rise in fertility, women's employment and family policies. This relation matches empirical evidence observed in European countries. Beyond a discrimination threshold, agents choose a tax rate equal to zero since the gains given by public policies are not enough to offset their costs. In this case, the effect through shifts in female wage

2. Apps and Rees (2004) find that both women's employment and fertility are higher in countries with individual rather than joint taxation, and in countries which help households through child care services rather than child payment. 
always prevails and a rise in discrimination stimulates fertility decisions.

To complement these results, the model is extended by introducing a child-rearing function in which parents' time are not perfect substitutes and a collective decision-making process within household. The first extension allows the analysis of gender discrimination effects on men's decisions and shows a negative effect of gender discrimination on the fathers' childrearing time. The second one is divided into two parts. First, it is assumed that spouses have different preferences, which allows the analysis of the bargaining power effect on overall household decisions. Secondly, it is assumed that the wife's bargaining power depends negatively on the gender discrimination. Bargaining power is affected by the relative wages of spouses, which are also influenced by changes in discrimination in the labor market. This extension allows us to study the way in which a collective approach to the decision-making process within the household modifies the results of the model (Apps \& Rees, 1997; Bourguignon \& Chiappori, 1992; Chiappori, 1997).

This work complements the literature relating fertility, the female labor supply and public spending decisions in which usually only women take care of children and a unitary decision-making process is used (Apps \& Rees, 2004). The model presented is based on Cavalcanti and Tavares (2007) and Galor and Weil (1996) in which the gender wage gap is due to differences in physical strength and reduces as the economy grows. The current chapter suggests to relate gender wage discrimination to cultural behaviors which may contribute to explain the persistence of gender wage gap and differences in European household decisions. In particular, this chapter focuses on the way in which gender discrimination may explain the positive relationship between fertility, female labor supply and family-friendly policies, while Cavalcanti and Tavares (2007) are mainly interested in the link between the female labor supply and the level of public spending. The chapter shows a U-shaped relationship between fertility and gender discrimination which implies that a decrease in gender discrimination may lead to a joint increase in fertility, female labor supply and family-friendly policies. By taking into account heterogeneity within couples, the model shows the role played by bargaining power on household decisions and allows the introduction of gender discrimination effect through shifts in bargaining power. Moreover, this chapter shows that discrimination in the labor market may be one of the explanatory factors for the low investment of men in domestic activities that all empirical studies reveal (Rizavi \& Sofer, 2009; Burda et al., 2007).

The chapter is structured as follows. Section 2 provides an overview of some empirical evidence regarding fertility rates, labor supply and family policies in OECD countries. In Section 3, a general equilibrium model with gender. discrimination is developed. Section 4 presents the main results. Section 5 proposes some extensions of the benchmark model in which are successively introduced a child-rearing function in which parents' time are not perfect substitutes, heterogeneity within the household and a collective household decision-making process. A discussion about the main results follows. Section 6 concludes. 


\section{Some empirical evidence}

Since the inversion of the cross-country correlation between fertility and the female labor supply in the middle of the 1980s, OECD countries with the lowest levels of female employment are also those that have low fertility rates (Bettio \& Villa, 1998). And the countries with the highest levels of female employment are also those that have high fertility rates (see Figure 4 in Appendix .1). In other words, a positive relationship occurs between these variables that is represented in Figure 1. It also seems that there is a positive relationship between the female labor supply and family-friendly policies in OECD countries (Del Boca \& Locatelli, 2007).
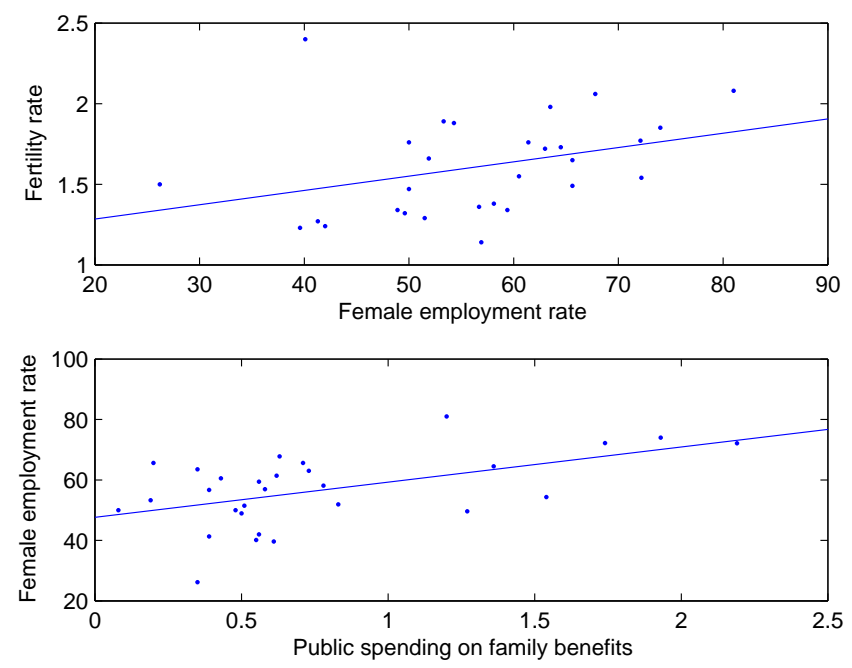

Figure 1: Family Decisions in OECD countries in 2000

Source: Total fertility rates correspond to the number of children aged 15 to 49 years old per woman. Female employment rates are those for persons aged 15-64 years. Public spending on family benefits is family spending on services percentage of GDP. The data come from the OECD database. All OECD countries are taken into account except Turkey.

This result leads to think that in countries where it is relatively easy for women to work and to have children, female employment and fertility both tend to be higher. Indeed, European countries which have the highest levels of fertility rates and female labor supply are also those that have high state intervention regarding the family. Family policies, by influencing the cost of having children, modify family behaviors in terms of female employment and fertility (D'Addio \& Mira d'Ercole, 2005). Hence, countries can be gathered into different clusters according to their respective behaviors in terms of the fertility rate, women's labor force participation rate and social policy (Chesnais, 1996; Hantrais, 1997). ${ }^{3}$

3. Some authors have organized countries in clusters according to their respective behavior concerning family policies. For example, according to the classification proposed by Gauthier (2002), the ten European countries of Table 1 could be divided into three groups. The first includes Denmark, while the second includes France, the United Kingdom, Austria, Germany and Ireland. And the last would comprise the 
In a cross-country comparison, factors such as labor market institutions (Adserà, 2004) or cultural attitudes (Fernandez et al., 2004) may influence these decisions. Here the analysis focuses on the role played by gender discrimination. Gender discrimination by acting on wages may be one explanatory factors of differences in household decisions across European countries. To illustrate this assumption, family decisions in a set of European countries have been employed. And two indicators of gender discrimination have been selected: the percentage of the gender wage gap which is unexplained by differences in characteristics between men and women, ${ }^{4}$ and the female economic activity rate as a percentage of the male rate. ${ }^{5}$ Both indexes do not measure exactly the same part of gender discrimination. While the former indicates differences in gender return of characteristics, the latter takes more into account barriers which women face when they want to participate in the labor market. A similar classification of countries selected is obtained in Table 1 by using both these indexes. ${ }^{6}$

Table 1. Gender Discrimination Index in 2000

\begin{tabular}{lcc}
\hline Countries & $\begin{array}{c}\text { Part of the Gender Wage Gap } \\
\text { Unexplained by Gender } \\
\text { Differences in Characteristics( \% }\end{array}$ & $\begin{array}{c}\text { Female Economic Activity } \\
\text { Rate (aged 15 and above) } \\
\text { as \% of Male Rate }\end{array}$ \\
\hline Denmark & 26,24 & 84 \\
\hline France & 27,72 & 76 \\
United Kingdom & 39,01 & 74 \\
Austria & 40,98 & 65 \\
Germany & 45,53 & 69 \\
Ireland & 50,78 & 52 \\
\hline Italy & 58,25 & 58 \\
Spain & 62,02 & 56 \\
Greece & 88,84 & 58 \\
Portugal & 117,44 & 71 \\
\hline
\end{tabular}

Southern European countries. We can see that this classification matches that of the discrimination index in Table 1.

4. This index has been computed for the year 2000 and is taken from Meurs and Ponthieux (2005) (Table A3). They analyze the composition of the gender wage gap by dividing it into the gap due to characteristics and that due to returns for these ten European countries. The index which represents the part of the gender wage gap that is unexplained by differences in characteristics corresponds to the gap due to returns divided by the total gap. The sample studied, in the current chapter, is limited to that of Meurs and Ponthieux, as it is difficult to procure the first discrimination index for many countries.

5. The female economic activity rate as a percentage of the male rate comes from the Human Development Report of 2002, published by the United Nations Development Program (UNDP).

6. Except for Portugal. In Table 1, as in Portugal the unexplained part is larger than the total gap, the first discrimination index is higher than $100 \%$. This seems to show that female workers have on average higher productive characteristics than male workers. 
As this chapter focuses on the effects of gender wage discrimination on household decisions the former indicator, "the part of the gender wage gap unexplained by gender differences in characteristics", has been employed to study the relationships between household decisions and gender discrimination.

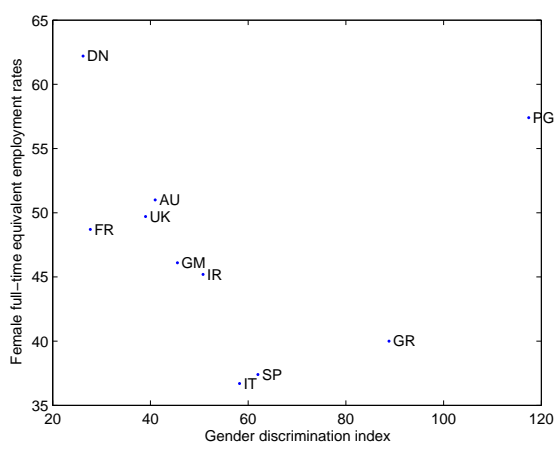

(a) Female full-time equivalent

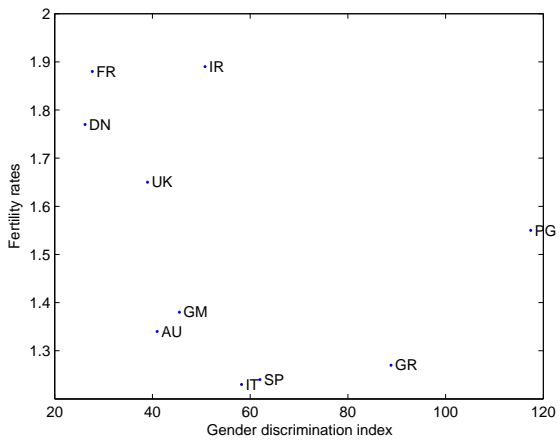

(c) Fertility Rate

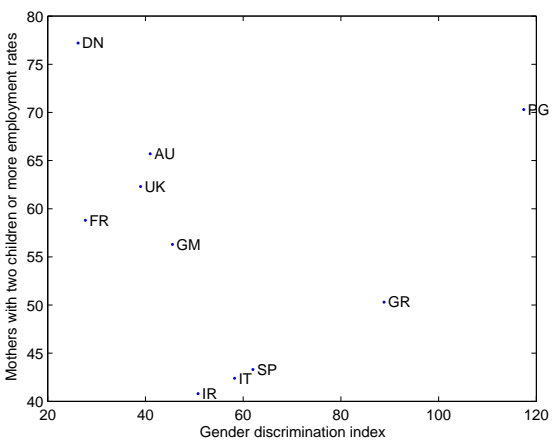

(b) Female with two or more children

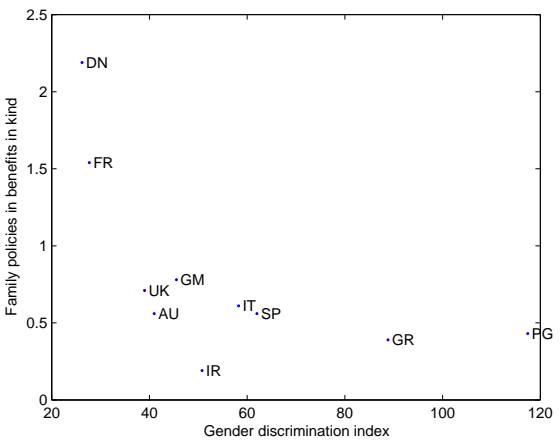

(d) Family-friendly Policies

Figure 2: Relations with Gender Discrimination Index

Source: Female employment rates of women with two ore more children are those for persons aged 25-54 years. Data come from the OECD database. Female full-time equivalent employment rate is calculated by dividing the full-time equivalent employment by the total population in 15-64 age-group. Full-time equivalent employment is defined as total hours worked divided by the average annual number of hours worked in full-time jobs. Data come from the European Commission.

Figures 2(a) to 2(d) give an insight of the kind of relationship that the theoretical model will try to match. They show, overall, a negative relationship between household decisions and the gender discrimination index. First, not surprisingly we find that a high degree of discrimination has a negative effect on female participation. This effect persists if female full-time equivalent employment or employment of women with two or more children are taken into account (Figure 2(a) and 2(b)). Discrimination by reducing the relative female wage within the couple discourages the participation of women into the labor market. Second, Figure 2(c) shows a decreasing relationship between fertility and gender discrimination, while traditionally it is expected that gender discrimination has a positive effect on fertility decisions by reducing female wage (Del Boca \& Locatelli, 2007). The Economist (2007) also points out a negative relationship between gender employment 
gap and fertility. And Hausmann et al. (2009) find that reducing gender inequalities may tend to increase fertility (See Figures 5(a) and 5(b) in Appendix .2). Taking into account the traditional positive effect of discrimination on fertility and the negative effect observed in Figure 2(c), a U-shaped relationship between fertility and gender discrimination may be considered. This U-shaped relationship can result from the existence of childcare services in countries. Finally, Figure 2(d) points out a negative effect of discrimination on family-friendly policies. Here the family-friendly policies correspond only to family spending on services as percentage of GDP (e.g. childcare services). So childcare services may influence fertility decisions which are both influenced by gender discrimination. To sum up data seem to show that gender discrimination has a negative effect on these three household decisions.

The next section presents the benchmark model that analyzes the way in which gender discrimination can affect these family decisions.

\section{The model}

The relationship between family decisions and gender discrimination is studied through a general equilibrium model with endogenous fertility, endogenous labor supply and endogenous size of government spending. The framework of the model is based on the article, written by Galor and Weil (1996) and that by Cavalcanti and Tavares (2007) which introduces public spending to the model. The economy is composed of men and women organized as couples and the level of family-friendly policies is endogenously determined by a vote of agents. Family policies are assumed to reduce the time that parents spend on their children.

In the economy there are two types of agents: the firm and the household.

\section{$3.1 \quad$ Firm}

\subsubsection{Firm decision}

All firms are identical. The production technology uses one production factor, labor. There are two kinds of worker, female workers, $L_{f}$, and male workers, $L_{m}$, which are perfect substitutes. The marginal productivity of men and women is the same.

The production function is,

$$
f\left(L_{f}+L_{m}\right)=A\left(L_{f}+L_{m}\right)
$$

where $A>0$ is the total productivity of factors.

Given the technology and the input prices, the representative firm chooses inputs in order to maximize its profits.

$$
\max _{L_{f}, L_{m}} \Pi\left(L_{f}, L_{m}\right)=f\left(L_{f}, L_{m}\right)-w_{m} L_{m}-\left(w_{f}+d\right) L_{f}
$$


Here the parameter $d$ captures the problem of discrimination and can be interpreted as the taste for discrimination of employers as in the discrimination theories based on discriminative preferences pioneered by Becker (1957). ${ }^{7}$ The problem of firm disappearance is avoid, as all firms are similar. The competition between firms will not lead to the disappearance of certain firms.

The first order conditions associated with the representative firm's problem are:

$$
w_{f}=A-d \text { and } w_{m}=A, \text { with } d \in[0, A[
$$

As this model takes place in an economy in which men and women have the same level of human capital, $d$ represents the wage gap between men and women per hour worked. Thus it determines the level of gender discrimination in the labor market.

For the same skills and working time, women receive a lower wage than men because of the gender discrimination, $w_{f}<w_{m} \cdot{ }^{8}$

\subsubsection{Discrimination}

In the model, a tasted-based discrimination in line with Becker (1957) is considered for two main reasons. Empirical evidence of taste-based discrimination from employers against women have been found in Hellerstein et al. (1999) and Hellerstein et al. (2002). Another explanation in favor of this choice is that gender wage gap may be explained by the attitudes towards women participation in the labor market. That is related to beliefs concerning the appropriate role of women within the society. Chichilnisky and Hermann Frederisken (2008) find a relation between persistence of gender wage gap and persistence of gender roles consideration, that may be directly linked to the attitude towards working women. This idea may be illustrated for example by the bad perception of working mothers in Germany, who are viewed as "mother-crow" (Fagnani, 2002). The perception of men towards the participation of their wife to the labor market reflects what they will feel concerning female employees if they are employers. ${ }^{9}$ Thus employers may consider that women should stay at home to take care of children and by employing a woman, will suffer from a disutility. The taste-based discrimination by assuming that employers suffer to employ women takes into account these feelings.

7. It is assumed that the gain of employed a woman rather than a man is equal to the psychological cost of the employer. So the representative employer employs both female and male workers. For a survey of gender discrimination theories see Altonji and Blank (1999) or Havet (2004).

8. The establishment of gender discrimination only takes into account the disadvantage of women in the labor market and not the possible advantage of men. So there is a social loss due to the discrimination.

9. Fernandez et al. (2004) analyze the evolution of attitudes of husband towards participation of their wifes to the labor market to explain changes in female labor supply. 


\subsection{Household}

\subsubsection{Timing of decisions}

Agents are living one period throughout they made decisions in two steps. First, agents vote for the taxation level which will be used to finance family-friendly policies. These policies concern childcare services which allow for a reduction in childrearing time of parents. ${ }^{10}$

In a second step, given the government spending, spouses make fertility, labor supply and individual consumption choices. These decisions are the result of the maximization of a weighted sum of individual utilities under the household budget constraint. In the maximization, the weightings are the bargaining power of each spouse. These decisions will be noted as intra-household decisions.

This problem is solved by backward induction. The second step allows the determination of individuals utilities in terms of public spending. And the first step determines the extent of public spending in the society.

\subsubsection{Second step: Intra-household decisions}

All households are identical in this society. Each agent has one unit of time which is divided between child care and paid work, ${ }^{11}$ and has the same level of human capital.

The preferences of spouses are first assumed to be the same and are represented by the following utility function:

$$
U_{i}=\beta \ln \left(c_{i}\right)+\gamma \ln (n) \text { with } i=f, m
$$

where $n$ is the number of children per couple, $c_{i}$ the individual consumptions and $\gamma+\beta=1$. Section 5.2 presents the results when spouses have different preferences.

Each spouses has one unit of time endowment that is divided between childcare and market activities. The budget constraint of the household is

$$
\left[w_{f}\left(1-h_{f}\right)+w_{m}\left(1-h_{m}\right)\right](1-\tau)=c_{f}+c_{m}
$$

where $h_{i}, i=f, m$ is parents' time spent on parental care and child-rearing, and $\tau$ is the tax rate. Notice that prices of consumption goods are normalized at one.

The time allocated by parents to their children is

$$
H=n h(g)=h_{f}+h_{m}
$$

10. The assumption of tax rate determination through a vote of agents is close to the one of Apps and Rees (2004) in which the authors assume that households choose the price of childcare services, but in the current chapter this decision is made individually.

11. The leisure is not introduced in the utility function as some recent studies show that men and women allocate pretty much the same time to leisure (Burda et al., 2007; Freeman \& Schettkat, 2005). 
where $h(g)$ represents the total time devoted by parents to each child. The time allocated by parents to children are first assumed to be perfect substitutes and then, in Section 5.1, not perfect substitutes.

In this model, government policies have an influence on household decisions through the childrearing technology,

$$
h(g)=\phi[1+g]^{-\varepsilon}
$$

where $\varepsilon>0$ and $\phi$ is the minimal time that parents have to devote to each child. More specifically, $\phi$ represents the time cost of children for parents when there is no public spending. The parameter $\varepsilon$ captures the efficiency of family policies. Public revenues are collected by the government through a proportional tax $\tau$ on household income. The government budget is balanced and taxes are employed to finance the per-couple government spending, $g$, intended to decrease the per-child cost of rearing children. ${ }^{12}$

The couple's program for intra-family decisions is

$$
\begin{gathered}
\max _{c_{f}, c_{m}, h_{f}, h_{m}} \theta\left[(1-\gamma) \ln \left(c_{f}\right)+\gamma \ln (n)\right]+(1-\theta)\left[(1-\gamma) \ln \left(c_{m}\right)+\gamma \ln (n)\right] \\
\text { s.t. }\left[w_{f}\left(1-h_{f}\right)+w_{m}\left(1-h_{m}\right)\right](1-\tau)=c_{f}+c_{m} \\
n=\frac{h_{f}+h_{m}}{h(g)}
\end{gathered}
$$

where $\theta$ is the bargaining power of the wife.

Notice that the opportunity cost of child-rearing is stronger for men than for women, because of $w_{f}<w_{m}$. Due to the gender discrimination, there is a specialization of gender roles within the couple based on comparative advantage and budget constraint (5). In the household only the woman takes care of children and the man spends all his time on the labor market. ${ }^{13}$

$$
h_{m}=0 \text { and } n h(g)=h_{f}
$$

Based on gender specialization, the couple's program becomes,

$$
\begin{gathered}
\max _{c_{f}, c_{m}, n} \theta\left[(1-\gamma) \ln \left(c_{f}\right)+\gamma \ln (n)\right]+(1-\theta)\left[(1-\gamma) \ln \left(c_{m}\right)+\gamma \ln (n)\right] \\
\text { s.t. }\left[w_{f}(1-n h(g))+w_{m}\right](1-\tau)=c_{f}+c_{m}
\end{gathered}
$$

12. This assumption is in line with the literature Apps \& Rees (2004) or Cavalcanti \& Tavares (2007). Regarding the shape of $h(g)$, I follow Cavalcanti \& Tavares (2007) except that the inputs in the childrearing function, parents' time and public services, may have not the same efficiency. The idea above this assumption is that in the public services, employees having a training in caring children may have a higher efficiency in childcare activities than parents.

13. As this chapter focuses on female labor supply decisions and their relation with discrimination, the case in which the time cost of children is very high such as $h_{m}>0, h_{f}=1$ is not reproduced. 
The woman's labor supply is given by,

$$
\left(1-h_{f}\right)=1-\frac{\gamma\left(w_{f}+w_{m}\right)}{w_{f}}
$$

The tax rate has two effects on the labor supply decisions. A high tax rate discourages the labor supply of the women. But it also reduces the opportunity cost of child-rearing and increases women's labor force participation. Due to the proportional form of the tax rate and the joint taxation of spouses within the household, the substitution effect and the income effect cancel each other out. ${ }^{14}$

The fertility choice is,

$$
n=\frac{\gamma\left(w_{f}+w_{m}\right)}{w_{f} h(g)}
$$

The number of children is limited by the time constraint of women and depends on household income. It is also a decreasing function of women's child-rearing opportunity cost, $w_{f} h(g)$. For a given level of public spending, an increase in discrimination which implies a drop in female wage, $w_{f}$, has a positive effect on fertility decisions.

The individual consumption decisions are

$$
c_{f}=\theta(1-\gamma)\left[w_{f}+w_{m}\right](1-\tau) \quad c_{m}=(1-\theta)(1-\gamma)\left[w_{f}+w_{m}\right](1-\tau)
$$

and depend on total available income and tax rate.

So, the intra-family decisions are expressed in relation to government spending.

\subsubsection{First step: Tax rate determination}

We can now turn at the first step during which each partner singly votes for the optimal level of public spending taking into account its effects on the women's trade-off between the labor market and child-rearing. So the choice of the public spending extent, is made at individual level and not at household level as in the article of Cavalcanti and Tavares (2007). This assumption introduces the discussion about voting systems when men and women vote for different tax rates in Section 5.2.

The budget of the government is balanced throughout and is defined such as,

$$
g=\tau(1-\gamma)\left(w_{f}+w_{m}\right)
$$

14. If a lump sum tax is considered the substitution effect outweighs the income effect. And the tax rate has a positive effect on female labor supply. Moreover, recent studies have pointed out that the labor supply elasticity is higher for women than for men and so the former should be less taxed than their partners (Alesina et al., 2007). If gender specific tax rates are introduced, the substitution effect prevails on the income effect and an increase in tax rate allows for a rise in female labor participation. The higher the male tax rate, the lower this effect. 
, where $\tau w^{m}$ is the tax on the husband's paid work and $\tau w_{f}(1-h(g) n)$ is the tax on the wife's paid work.

Each partner singly fixes the tax rate which maximizes his/her expected indirect utility,

$$
\max _{g_{i}} V_{i}=(1-\gamma) \ln \left[c_{i}\left(g_{i}\right)\right]+\gamma \ln \left[n\left(h\left(g_{i}\right)\right)\right], \quad i=f, m
$$

The preferred tax rate of agents is given by the following expression, ${ }^{15}$

$$
\tau_{i}=\frac{\gamma \varepsilon}{\gamma \varepsilon+(1-\gamma)}-\frac{1}{\left(w_{f}+w_{m}\right)(\gamma \varepsilon+(1-\gamma))}, \quad i=f, m
$$

Men and women choose the same level of tax rate. There is a consensus concerning the expected tax rate within the society. The tax rate is positively linked with the household income. The extent of the tax rate also depends on the relative preferences of spouses for children and on the public spending efficiency, $\varepsilon$. The lower the female wage, the higher the tax rate. Finally, if wages are relatively high, the higher the preferences for children, the higher the tax rate.

Before examining the equilibrium, some intermediate results can be quoted:

$$
w_{m}=A, \quad w_{f}=A-d, \quad L_{f}=\left(1-h_{f}\right) \quad \text { and } \quad L_{m}=\left(1-h_{m}\right)
$$

where $w_{m}, w_{f}, L_{f},\left(1-h_{f}\right), L_{m}$ and $\left(1-h_{m}\right)$ are respectively male wage, female wage, women's labor demand, women's labor supply, men's labor demand and men's labor supply.

All decisions such as fertility, labor supply, individual consumptions and public spending depend on both discrimination, $d$, and preferences.

\section{Implications of gender discrimination}

At the equilibrium, two solutions could be identified by different gender discrimination levels. An interior solution characterized by a positive tax rate, $\tau>0$, and a corner solution specified by a tax rate equal to zero, $\tau=0$ if $A>d>2 A-\frac{1}{\gamma \varepsilon}$.

\subsection{Interior Solution}

If $d<2 A-\frac{1}{\gamma \varepsilon}$, the marginal gain given by public spending compensates for the marginal cost of the latter and adults vote for a strictly positive tax rate, $\tau>0$.

The tax rate,

$$
\tau=\frac{\gamma \varepsilon}{\gamma \varepsilon+(1-\gamma)}-\frac{1}{(2 A-d)(\gamma \varepsilon+(1-\gamma))}
$$

15. For intermediate results see Appendix .3. 
is a decreasing function of the gender discrimination, $\frac{\partial \tau}{\partial d}<0$ and so the higher the gender discrimination, the smaller the tax rate. Moreover, the condition under which the tax rate $\tau$ is positive could also be analyzed as an efficiency constraint concerning the childrearing technology which is related to family policies, in other words a constraint on $\varepsilon$. Indeed, if the welfare services offered by the state are too low, the voters choose a low tax rate. The efficiency condition required for the existence of public policies depends on the relative preferences of agents such that the higher the preferences for consumption, the lower the condition.

The number of children chosen by the couple is given by,

$$
n=\frac{\gamma(\gamma \varepsilon)^{\varepsilon}(2 A-d)[1+(1-\gamma)(2 A-d)]^{\varepsilon}}{\phi(\gamma \varepsilon+(1-\gamma))^{\varepsilon}(A-d)}
$$

Proposition 1 There is a U-shaped relationship between fertility and gender discrimination if $\varepsilon>\left(1+\frac{1}{2 A(1-\gamma)}\right)$. If this condition is not satisfied, the fertility decision is an increasing function of gender discrimination.

Proof. See Appendix .4

The way gender discrimination affects fertility decisions depends on the efficiency of public spending. The efficiency condition required to have a U-shaped relationship between fertility and discrimination, is a decreasing function of relative preferences for consumptions. In other words, if spouses favor consumptions more than children they accept to use childcare services for lower level of quality.

To get a better understanding at this U-shaped relationship the effects through which discrimination affects fertility decisions can be presented. By changing woman's opportunity cost of child-rearing, $h(g) w_{f}$, discrimination leads to two price effects. The direct price effect implies that a drop in female wage, $w_{f}$, due to a higher discrimination level, reduces the child-rearing opportunity cost in terms of earnings. Thus, as women are paid less, they are discouraged from participating in the labor market and they might decide to have more children. This effect has a positive impact on childbearing choices.

The indirect price effect comes from changes in the woman's opportunity cost in terms of time, $h(g)$. A higher discrimination level leads to less public spending and increases in turn the woman's opportunity cost in terms of time. This has a negative impact on the fertility choice.

Finally, an increase in discrimination also implies an income effect which can be set out as follows. A higher discrimination level reduces the female wage and therefore the household income. Having children is costly, a reduction in the household income discourages the couple from having more children. The income effect therefore plays negatively on the fertility choice.

To sum up, firstly if the level of gender discrimination is sufficiently low, the negative effects prevail and a higher gender discrimination level discourages the fertility choice, 
$\frac{\partial n}{\partial d}<0$. Notice that this negative relation exists only in the decreasing part of the U-shaped curve. The set of countries presented in Section 2 are in this part of the curve. However, when the discrimination is beyond a certain threshold, the positive effect outweighs the negative effects and childbearing decision becomes an increasing function of the gender discrimination.

The woman's labor supply is given by,

$$
\left(1-h_{f}\right)=1-\frac{\gamma(2 A-d)}{(A-d)}
$$

The woman's labor supply is negatively correlated with the gender discrimination level, $\frac{\partial\left(1-h_{f}\right)}{\partial d}<0$. The higher the gender discrimination level, the smaller the women's labor force participation. A higher level of discrimination against women decreases women's wage and discourages women's labor force participation.

If $\varepsilon>\left(1+\frac{1}{2 A(1-\gamma)}\right)$, in the decreasing part of the U-shaped curve a decrease in discrimination leads to a joint increase in fertility and female labor supply as it has been observed in the first Section of this chapter.

Individual consumptions are also negatively correlated with the discrimination level. A higher gender discrimination level reduces the household income for a given working time and decreases individual consumptions,

$$
c_{f}=\theta(1-\gamma) \frac{[(1-\gamma)(2 A-d)+1]}{(\gamma \varepsilon+(1-\gamma))} \quad c_{m}=(1-\theta)(1-\gamma) \frac{[(1-\gamma)(2 A-d)+1]}{(\gamma \varepsilon+(1-\gamma))}
$$

\subsection{Corner solution}

In the corner solution, as the gender discrimination level is very high, $d>2 A-\frac{1}{\gamma \varepsilon}$, the marginal gain given by public spending does not compensate for the marginal cost of the latter. Adults vote for a tax rate equal to zero, $\tau=0$.

The number of children chosen by the household,

$$
n=\frac{\gamma(2 A-d)}{(A-d) \phi}
$$

is positively associated with gender discrimination, $\frac{\partial n}{\partial d}>0$. A higher level of gender discrimination encourages fertility. The price effect outweighs the income effect as there is no indirect price effect which plays through shifts in public spending. This result coincides with the literature which specifies that childbearing decisions are negatively linked to female wages (Del Boca \& Locatelli, 2007).

If there is a U-shaped relationship between fertility and discrimination, that means $\varepsilon>\left(1+\frac{1}{2 A(1-\gamma)}\right)$, this solution will be located in the increasing part of the U-shaped curve. The gender discrimination level still has a negative impact on the female labor supply, $\left(1-h_{f}\right)=1-\frac{\gamma(2 A-d)}{(A-d)}$. 
Individual consumptions are still negatively correlated with the discrimination level. A higher discrimination level reduces the household income for a fixed working time and decreases individual consumptions,

$$
c_{f}=\theta(1-\gamma)(2 A-d) \text { and } c_{m}=(1-\theta)(1-\gamma)(2 A-d)
$$

To sum up, gender discrimination, by acting on wages, modifies the allocation of tasks within the household. ${ }^{16}$ If discrimination is not too high, its increase raises the cost of having children and puts off the childbearing decision. Beyond a discrimination threshold there is an inversion of this relationship and households have more children. As gender discrimination reduces the female wage, its increase discourages the entry of women into the labor market. By remaining at home for longer, the female demand for public services decreases and spouses vote for a lower tax rate.

Table 2. Discrimination effects on household decisions

\begin{tabular}{lcc}
\hline$\tau$ & $\left(1-h_{f}\right)$ & $n$ \\
\hline$(-)$ & $(-)$ & U-shaped if $\varepsilon>\left(1+\frac{1}{2 A(1-\gamma)}\right)$ \\
& & $(+)$ if $\varepsilon<\left(1+\frac{1}{2 A(1-\gamma)}\right)$ \\
\hline
\end{tabular}

Some extensions of the benchmark model are now proposed in order to analyze the effects of gender discrimination on men's decisions, and on household decisions when spouses differ in preferences.

\section{$5 \quad$ Further Issues}

The purpose of the following extension is to study the gender discrimination effects on men's behavior. Indeed, as men do not take care of children in the benchmark model, gender discrimination does not affect the male labor supply. However, by introducing into the benchmark model a childrearing function in which parents' time are not perfect substitutes, men's decisions are no longer independent of gender discrimination.

\subsection{Parents' childrearing time}

Even if data show that men spend less time with children than women, they are all the same allocating a small part of their available time to child care (Aguiar \& Hurst, 2007). Pailhé and Solaz (2008) find that parents are unwilling to leave their parental occupation and show that the time allocated to children by both parents are not perfect substitutes.

A new childrearing function is taking into account,

16. These decisions also depend on cultural attitudes, see Fernandez et al. (2004). 


$$
h(g) n=\left(h_{f}\right)^{\eta}\left(h_{m}\right)^{(1-\eta)}
$$

where $\eta$ represents the efficiency of female childrearing time and $1-\eta$ represents the efficiency of male childrearing time. ${ }^{17}$ Men, like women, have to trade off between childrearing time and working time. The higher $\eta$ is, the more time women devote to children and vice versa for men.

The new form of the childrearing function does not change the chosen level of tax rate but modifies the condition on efficiency policies, $\varepsilon>\frac{(2 \eta-1)}{2 A(1-\gamma)}+(2 \eta-1)$, under which a U-shaped relationship between gender discrimination and fertility can be found (see Appendix .5). In this case, there are also an interior and a corner solution. I focus on results when agents vote for a positive tax rate.

$$
n=\frac{\gamma^{\varepsilon+1} \eta^{\eta} \varepsilon^{\varepsilon}(2 A-d)(1-\eta)^{1-\eta}[1+(1-\gamma)(2 A-d)]^{\varepsilon}}{\phi(A-d)^{\eta} A^{1-\eta}(\gamma \varepsilon+(1-\gamma))^{\varepsilon}}
$$

Fertility decisions depend now on child opportunity cost of both parents which depends on their relative efficiency in childrearing time and wages. Notice that the opportunity cost in terms of earnings changes in the same way for men and women following an increase in productivity $A$, but only changes for women following an increase in discrimination level.

Gender discrimination still has a negative impact on women's labor supply, $1-h_{f}$, the tax rate level and the individual consumptions. However, gender discrimination has a positive effect on men's labor supply, $1-h_{m}$. As higher gender discrimination discourages his wife from participating to the labor force, the husband has to work longer in order to compensate for the loss of income due to the decrease in his wife's working time. In the decreasing part of the U-shaped, a positive relationship between fertility and female labor supply decisions still exists.

The woman's childrearing time is positively linked to the discrimination level, $\frac{\partial h_{f}}{\partial d}>0$ :

$$
h_{f}=\frac{\eta \gamma(2 A-d)}{(A-d)}
$$

While the man's childrearing time is negatively related with the discrimination level, $\frac{\partial h_{m}}{\partial d}<0$ :

$$
h_{m}=\frac{(1-\eta) \gamma(2 A-d)}{A}
$$

17. If $\eta=1$, there is a total specialization of gender roles within the household as in the benchmark model. That means only the women will take care of children. If $\eta=0$ it is the reverse case, but data do not confirm this kind of situation. Finally, $0<\eta<1$ implies a share of childrearing time between spouses. It is usually assumed that women due to their biological characteristics are more efficient in activities concerning children than men. 
Women are devoting more time to children than men because of gender discrimination, whatever $\eta$. Thus, as women are discriminated against in the labor market, men have to offset the loss of income due to the gender discrimination by working longer and decreasing their childrearing time. Discrimination in the labor market may therefore be one of the explanatory factors for the low investment of men in domestic activities that all empirical studies reveal (Rizavi \& Sofer, 2009; Burda et al., 2007). Indeed, in the Southern European countries such as Spain where gender discrimination is high, the participation of men in the domestic sphere is low. Meanwhile in the Northern European countries such as Denmark, where gender discrimination is lower, male participation in domestic activities is much greater.

To sum up, the new shape of the childrearing function allows us to take into account the effects of gender discrimination on individual male decisions and more specifically the contribution of men to domestic activities. Due to the new trade-off for men between children and market work, a negative relationship is observed between the level of gender discrimination and the level of men's childrearing time. This result lets us presume that male employment is negatively related to the extent of the family policies, as the latter is still negatively related to gender discrimination. ${ }^{18}$

Up to now, there is no real discussion about the voting process as agents choose the same level of public spending. It is no longer the case when heterogeneity in preferences are introduced in the model.

\subsection{Heterogeneity within household and a collective approach to the decision-making process}

\subsubsection{Heterogeneity of preferences within the household}

It is now assumed that preferences are distributed in regard to gender.

The program of a representative couple after the specialization of gender roles is given as follows,

$$
\begin{gathered}
\max _{c_{f}, c_{m}, n} \theta\left[\beta_{f} \ln \left(c_{f}\right)+\gamma_{f} \ln (n)\right]+(1-\theta)\left[\beta_{m} \ln \left(c_{m}\right)+\gamma_{m} \ln (n)\right] \\
\text { s.t. }\left[w_{f}(1-h(g) n)+w_{m}\right](1-\tau)=c_{f}+c_{m}
\end{gathered}
$$

where $\gamma_{i}+\beta_{i}=1, i=m, f,{ }^{19}$ and the model is solved in two steps as in the benchmark model.

18. As in Cavalcanti and Tavares (2007).

19. This assumption allows us to change individual preferences without modifying the bargaining powers within the household. Moreover, this assumption does not limit the set of possibilities concerning preferences. 
As spouses have different preferences, they choose different levels of taxation:

$$
\tau_{i}=\frac{\gamma_{i} \varepsilon}{\left(\left(1-\gamma_{i}\right)+\gamma_{i} \varepsilon\right)}-\frac{\left(1-\gamma_{i}\right)}{(2 A-d)\left(\theta\left(1-\gamma_{f}\right)+(1-\theta)\left(1-\gamma_{m}\right)\right)\left(1-\gamma_{i}+\gamma_{i} \varepsilon\right)}
$$

Proposition 2 If women have higher preferences for children than men, $\gamma_{f}>\gamma_{m}$, women would vote for a higher tax rate than men, $\tau_{f}-\tau_{m}>0$.

Proof.

$$
\begin{gathered}
\tau_{f}-\tau_{m}=\frac{\left(\gamma_{f}-\gamma_{m}\right) \varepsilon[(1-\tilde{\beta})+(2 A-d)]}{(2 A-d)\left(1-\gamma_{f}(1-\varepsilon)\right)\left(1-\gamma_{m}(1-\varepsilon)\right)} \\
\tau_{f}-\tau_{m}>0 \Leftrightarrow \gamma_{f}>\gamma_{m}
\end{gathered}
$$

The economy is only composed of men and women who prefer respectively the tax rates $\tau_{m}$ and $\tau_{f}$. The applicable tax rate within the society may depend on the voting turnout rates, the voting rights and also on the chosen political process. If women have no right to vote or are constrained in their voting, under majority rule the applicable tax rate is the men's one. It would also be the case if men participate much more to the vote than women.

It is assumed the proportions of men and women are the same, women have voting rights and are free in their voting decisions, and female and male voter turnout rates are the same. As there is no majority in society, every tax rate between that preferred by men and that preferred by women could be a solution. Under majority rule we can not decide which one of these tax rates will be applied.

For this reason we turn to another political process using a probabilistic voting model (Lindbeck \& Weibull, 1987; Persson \& Tabellini, 2000). So a two-candidate probabilistic voting model is modeled. Agents are casting their votes on one of two office-seeking candidates. Voters' preferences may differ not only over family policy, but also over orthogonal policy dimensions about which the applicants cannot make binding commitments. In a probabilistic equilibrium, both candidates propose the same policy, which maximizes a weighted sum of voters utilities. In this case, the weights are the same for both groups:

$$
\max _{g}\left[\frac{1}{2} V_{f}\left(c_{f}, n\right)+\frac{1}{2} V_{m}\left(c_{m}, n\right)\right]
$$

where $V_{f}$ and $V_{m}$ are respectively the indirect utilities of women and men. ${ }^{20}$

When spouses have different preferences tax rate, female labor supply and fertility decisions are influenced by the bargaining powers. Up to now, these decisions were only dependent on spouses' preferences and wages.

20. For intermediate results see Appendix .6. 
The tax rate is given by the following expression:

$$
\begin{aligned}
\tau(d, \theta)= & \frac{\varepsilon\left(\gamma_{f}+\gamma_{m}\right)}{B}-\frac{\left(1-\gamma_{f}\right)+\left(1-\gamma_{m}\right)}{(2 A-d) B\left[\left(1-\gamma_{f}\right) \theta+\left(1-\gamma_{m}\right)(1-\theta)\right]} \\
& \text { with } B=\left[\left(1-\gamma_{f}\right)+\left(1-\gamma_{m}\right)+\varepsilon\left(\gamma_{f}+\gamma_{m}\right)\right]
\end{aligned}
$$

The woman's labor supply is given by,

$$
\left(1-h_{f}(d, \theta)\right)=1-\frac{(2 A-d)\left(\theta \gamma_{f}+(1-\theta) \gamma_{m}\right)}{(A-d)}
$$

Proposition 3 If women value children more than men, $\gamma_{f}>\gamma_{m}$, an increase in the wife's bargaining power, $\theta$, will reduce both the tax rate and the time spent by women in the labor market. But this rise has a non-monotonous effect on fertility decision.

\section{Proof.}

$$
\begin{gathered}
\frac{\partial \tau(d, \theta)}{\partial \theta}=\frac{\left[\left(1-\gamma_{f}\right)+\left(1-\gamma_{m}\right)\right]\left(\gamma_{m}-\gamma_{f}\right)}{(2 A-d) B\left[\left(1-\gamma_{f}\right) \theta+\left(1-\gamma_{m}\right)(1-\theta)\right]^{2}}<0 \text { if } \gamma_{f}<\gamma_{m} \\
\frac{\partial t_{f}(d, \theta)}{\partial \theta}=\frac{(2 A-d)\left(\gamma_{m}-\gamma_{f}\right)}{(A-d)}<0 \text { if } \gamma_{f}<\gamma_{m}
\end{gathered}
$$

The fertility is,

$$
\begin{gathered}
n=\frac{(2 A-d)\left(\varepsilon\left(\gamma_{f}+\gamma_{m}\right)\right)^{\varepsilon} \tilde{\beta}[1+(2 A-d)(1-\tilde{\beta})]^{\varepsilon}}{\phi(A-d)\left[\left(1-\gamma_{f}\right)+\left(1-\gamma_{m}\right)+\left(\gamma_{f}+\gamma_{m}\right) \varepsilon\right]^{\varepsilon}} \\
\text { with } \tilde{\beta}=\left(\theta \gamma_{f}+(1-\theta) \gamma_{m}\right)
\end{gathered}
$$

If $\gamma_{f}>\gamma_{m}$, an increase in $\theta$ will both increase the total time spent by women on children, $h_{f}$, and reduce public spending, $g$. The final effect on the time spent by women on each child, $h(g)$, is non-linear and depends on the public spending efficiency and on its level, respectively $\varepsilon$ and $g$. Hence, as the cross derivative of $h(g)$ could be positive or negative in terms of $\varepsilon$ and $g\left(\frac{\partial^{2} h(g)}{\partial g \partial \varepsilon}<0\right.$ or $\left.>0\right)$, the effect of an increase in $\theta$ on fertility is non-monotonous. Two kinds of situation emerge and can be summarized by Figure 3.

The individual consumptions are,

$$
c_{f}=\frac{\theta\left(1-\gamma_{f}\right)\left(\left(1-\gamma_{f}\right)+\left(1-\gamma_{m}\right)\right)[(2 A-d)(1-\tilde{\beta})+1]}{(1-\tilde{\beta}) B} \quad c_{m}=\frac{(1-\theta)\left(1-\gamma_{m}\right)\left(\left(1-\gamma_{f}\right)+\left(1-\gamma_{m}\right)\right)[(2 A-d)(1-\tilde{\beta})+1]}{(1-\tilde{\beta}) B}
$$

An increase in female bargaining power rises female consumption as it increases the share of the household income perceived by women and consequently decreases male consumption. 


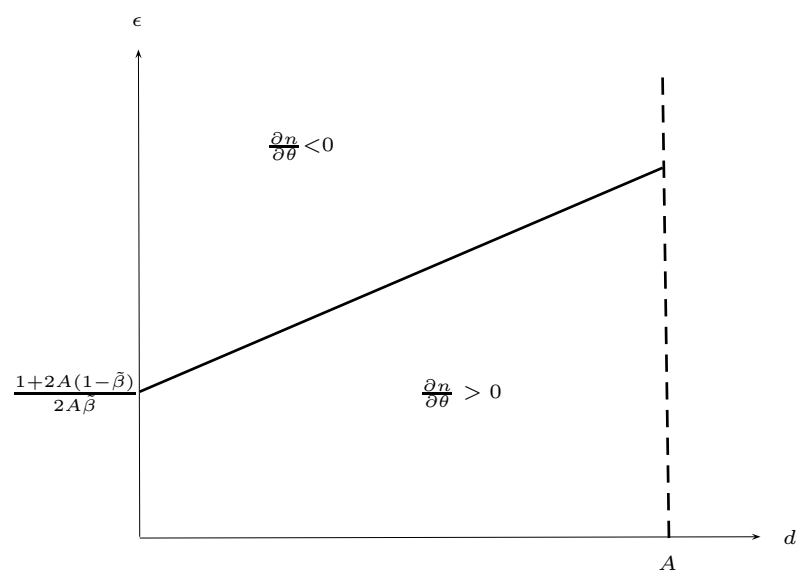

Figure 3: Effect of women's bargaining power on fertility

The effects of discrimination on household decisions are still the same. Indeed, a Ushaped relationship between gender discrimination and fertility can also be found, and gender discrimination still has a negative effect on women's labor supply, tax rate level and individual consumptions.

\subsubsection{Collective approach to the decision-making process}

The bargaining power of each member within the household is now assumed to depend on gender discrimination, $d$. The wife's bargaining power is assumed to be negatively linked to the gender discrimination level, $\frac{\partial \theta(d)}{\partial d}<0$. The effect of discrimination on household decisions now depends on the relative preferences of parents for children.

If men value children more than women, $\gamma_{m}>\gamma_{f}$, gender discrimination still has a negative effect on the female labor supply and the tax rate. However, if it is women who value children the most, $\gamma_{f}>\gamma_{m}$, the discrimination effect on these decisions is ambiguous. Gender discrimination plays a part in the determination of these decisions in two different ways; a direct effect and an indirect effect through the bargaining power shifts (see Appendix .7). If the direct effect prevails, the gender discrimination still has a negative effect on both decisions, as has already been found. However, if the indirect effect prevails, an increase in the gender discrimination level has a positive impact on the female labor supply and on the tax rate. As gender discrimination reduces the female bargaining power within the household and men pay less attention to children, an increase in the discrimination plays in favor of consumption. Hence, women rise their labor supply and the chosen tax rate is higher.

The relationship between fertility and gender discrimination is now less clear, as it depends on preferences and assumptions made concerning variables of the model such as the efficiency of family policies, $\varepsilon$, and the total productivity of factors, $A$ (see Appendix .7). 
If men value children more than women, a rise in discrimination increases fertility if the effect through the female time allocated to children outweighs the effect through public spending shifts. If it is not the case the global effect on fertility is negative. Now, if women value children more than men, $\gamma_{f}>\gamma_{m}$, the analysis becomes more complex as the global effect of discrimination on fertility decision depends on the relative extent between the direct effect and the effect through bargaining power shifts. Indeed, on the one hand discrimination reduces female wage but on the other hand, it also decreases the female bargaining power pushing women to increase their participation, as explained previously. To understand the whole effect of discrimination on fertility decision we can rewrite its expression,

$$
n=\frac{h_{f}[1+g]^{\epsilon}}{\phi}
$$

and analyze the discrimination effect on factors determining fertility when $\gamma_{f}>\gamma_{m}$ :

$$
\begin{aligned}
& \frac{\partial h_{f}(d, \theta(d))}{\partial d}=\frac{\partial h^{f}(d, \theta(d))}{\partial d}+\frac{\partial h_{f}(d, \theta(d))}{\partial \theta} \quad \frac{\partial \theta(d)}{\partial d} \\
& (+) \quad(+) \quad(-) \\
& \frac{\partial g(d, \theta(d))}{\partial d}=\frac{\partial g(d, \theta(d))}{\partial d}+\frac{\partial g(d, \theta(d))}{\partial \theta} \quad \frac{\partial \theta(d)}{\partial d} \\
& (-) \quad(-) \quad(-)
\end{aligned}
$$

If the direct effect outweighs the effect through bargaining power shifts, a rise in discrimination increases the time allocated by women to children and decreases the child care services and, in accordance to the prevailing effect the global effect on fertility could be positive or negative. Notice that the efficiency of public spending, $\varepsilon$, influences the overall effect and the more efficient the public spending, the more likely the final effect on fertility will be positive.

Finally, while discrimination still has a negative effect on female consumption as it reduces both female wage and female bargaining power, the total effect on male consumption depends on the relative extent of the direct effect and the effect through bargaining power shifts. The latter effect being positive as discrimination increases male bargaining power.

\section{Conclusion}

In this chapter, the relationships between gender discrimination and household decisions have been presented. The model shows that different levels of gender discrimination may explain divergences in household decisions across countries. The solution shows a Ushaped relationship between fertility and gender discrimination if the efficiency in public 
spending is sufficiently high. A drop in the discrimination level may lead to a related rise in fertility, women's employment and family policies. These results match the positive correlation between childbearing and women's labor supply which has been observed since the mid-1980s in OECD countries. Moreover, female labor force participation and the size of public spending vary in the same way as in Cavalcanti and Tavares (2007). The model also shows that if gender discrimination is very high, the marginal gain given by public spending does not compensate for the marginal cost of the latter, so agents vote for a tax rate equal to zero. The model points out that discrimination in the labor market may be one of the explanatory factors for the low investment of men in domestic activities that all empirical studies reveal. Finally, the role played by preferences is also analyzed in the current chapter.

Some extensions of this chapter can be proposed. Discrimination can be analyzed as a social norm which differs from country to country (Fernandez, 2007). Another potential extension could be to study the dynamics of the model by modeling, for example, an overlapping generation structure. In a dynamics perspective, the depreciation of human capital due to specialization in domestic activities for women would influence household decisions as it would affect both the gender wage gap and spouses' bargaining power. An econometric analysis may also be done to test the relevance of this model.

\section{Appendices}

\section{A Empirical Evidence}

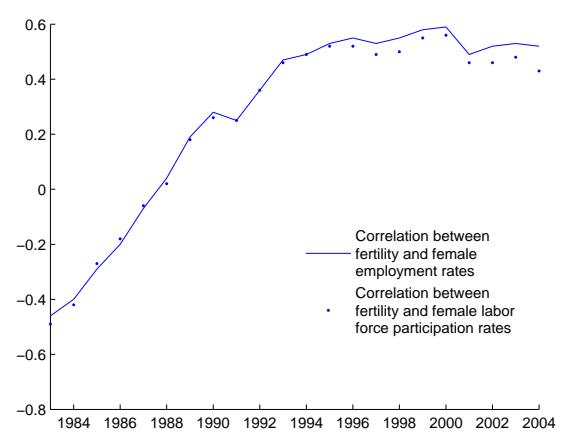

Figure 4: Correlation between fertility rates and female activity rates (line) and between fertility rates and female labor participation rates (dashed line)

Source: These correlations have been calculated for ten European countries: Austria, Denmark, France, Germany, Greece, Ireland, Italy, Portugal, Spain and the United Kingdom. Data come from the OECD database. 


\section{B Gender inequalities index}

Using the gender inequalities index developed by Hausmann et al. (2009) for developed and developing countries, Figure 5(a) shows a U-shaped relationship between fertility and gender inequalities. Figure 5(b) points out a negative relationship between fertility and gender inequalities in the selected countries of Section 2 for which the gender inequalities index is available; Denmark, Greece, Ireland, Italy, Portugal, Spain and The United Kingdom.

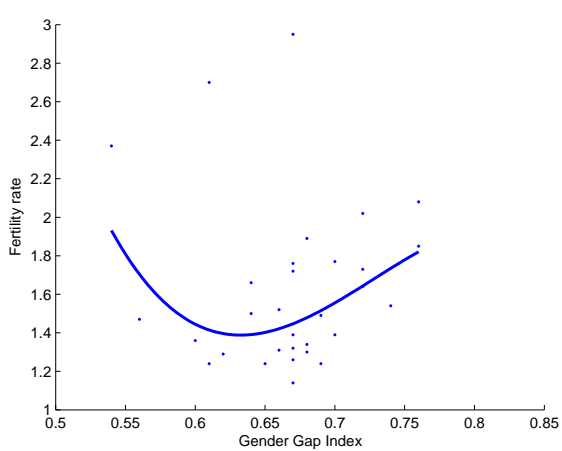

(a)

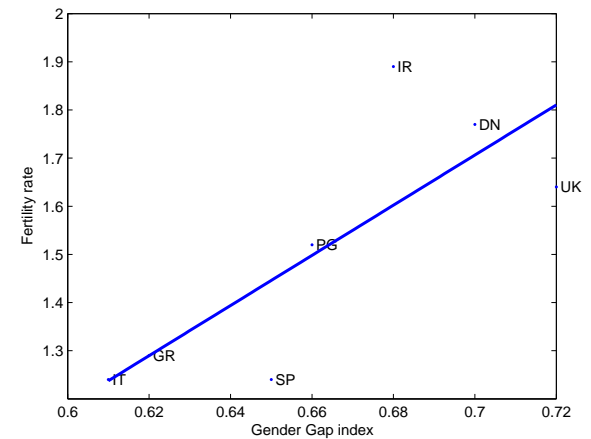

(b)

Figure 5: Fertility rate and gender inequalities index in 2000

Source: Fertility rates are coming from the World Bank. The gender gap index comes from Hausmann et al. (2009). This index is defined between 0 and 1 scale with $0=$ inequality and 1 = equality. In Figure 5 (a) countries selected correspond to those for which the index is available in 2000 including Australia, Belgium, Canada, Croatia, Czech Republic, Denmark, Finland, Greece, Hungary, Iceland, Ireland, Israel, Italy, Japan, Korea Rep., Latvia, Lithuania, Mexico, The Netherlands, New Zealand, Norway, Poland, Portugal, Romania, Slovak Republic, Slovenia, Spain, Sweden, Switzerland, Turkey, The United Kingdom.

\section{Tax rate determination}

First order condition of the maximization of spouses' indirect utilities:

$$
\frac{\gamma \varepsilon}{(1+g)}-\frac{(1-\gamma)}{(1-\gamma)\left(w_{f}+w_{m}\right)-g}=0 \quad \text { with } \quad \frac{\partial^{2} V_{i}}{\partial g_{i}^{2}}<0
$$

From this condition the expression of public spending can be found,

$$
g=\frac{\left[\gamma \varepsilon\left(w_{f}+w_{m}\right)-1\right](1-\gamma)}{(\varepsilon \gamma+1-\gamma)}
$$

and also the time devoted by women to each child:

$$
h(g)=\phi\left[\frac{\gamma \varepsilon\left[1+\left(w_{f}+w_{m}\right)(1-\gamma)\right]}{(\varepsilon \gamma+1-\gamma)}\right]^{-\varepsilon}
$$




\section{C.1 Proof of Proposition 1}

$$
\begin{gathered}
\frac{\partial n(d)}{\partial d}=\frac{Z[1+(1-\gamma)(2 A-d)]^{\varepsilon-1}[[1+(1-\gamma)(2 A-d)] A-(2 A-d) \varepsilon(1-\gamma)(A-d)]}{(A-d)^{2}} \\
\text { with } Z=\frac{\gamma(\gamma \varepsilon)^{\varepsilon}}{\phi(\varepsilon \gamma+1-\gamma)^{\varepsilon}} \\
\frac{\partial n(d)}{\partial d}<0 \text { feasible } \Leftrightarrow \varepsilon>\left(1+\frac{1}{2 A(1-\gamma)}\right) \text { with } d \in[0, A[
\end{gathered}
$$

\section{Intermediate results of Section 5.1}

From this program of the couple can be deduced the new expressions of household decisions in Section 5.1,

$$
\max _{c_{f}, c_{m}, h_{f}, h_{m}} \theta\left[\beta \ln \left(c_{f}\right)+\gamma \ln (n)\right]+(1-\theta)\left[\beta \ln \left(c_{m}\right)+\gamma \ln (n)\right]
$$

$$
\begin{gathered}
\text { s.t. }\left[w_{f}\left(1-h_{f}\right)+w_{m}\left(1-h_{m}\right)\right](1-\tau)=c_{f}+c_{m} \text { and } \gamma+\beta=1 \\
n=\frac{\left(h_{f}\right)^{\eta}\left(h_{m}\right)^{(1-\eta)}}{h(g)}
\end{gathered}
$$

The condition under which the U-shaped curve exists is given by,

$$
\begin{gathered}
\frac{\partial n(d)}{\partial d}=s(-(1-\gamma) \varepsilon(2 A-d)(A-d)+[1+(1-\gamma)(2 A-d)][A(2 \eta-1)+d(1-\eta)]) \\
\text { with } s=\frac{\gamma^{\varepsilon+1} \eta^{\eta} \varepsilon^{\varepsilon}(1-\eta)^{(1-\eta)}}{\phi(\varepsilon \gamma+1-\gamma)^{\varepsilon} A^{(1-\eta)}} \frac{[1+(1-\gamma)(2 A-d)]^{\varepsilon-1}}{(A-d)^{\eta+1}} \\
\frac{\partial n(d)}{\partial d}<0 \text { feasible } \Leftrightarrow \varepsilon>\frac{(2 \eta-1)}{2 A(1-\gamma)}+(2 \eta-1) \text { with } d \in[0, A[
\end{gathered}
$$

\section{E $\quad$ Intermediate results of Section 5.2}

Results coming from the intra-family decisions program are:

$$
\begin{gathered}
c_{f}(g)=\theta\left(1-\gamma_{f}\right)(1-\tau(g))[2 A-d] \\
c_{m}(g)=(1-\theta)\left(1-\gamma_{m}\right)(1-\tau(g))[2 A-d] \\
n(g)=\frac{(2 A-d)\left((1-\theta) \gamma_{m}+\theta \gamma_{f}\right)}{\phi[1+g]^{-\varepsilon}(A-d)}
\end{gathered}
$$


Expressions of spouses' indirect utility are,

$$
V_{i}=\gamma_{i} \ln (n(g))+\left(1-\gamma_{i}\right) \ln \left(c_{i}(g)\right) \text { with } \mathrm{i}=\mathrm{f}, \mathrm{m}
$$

Following the probabilistic voting rule and using the government budget constraint $(\tau(g)=$ $\left.\frac{g}{(2 A-d)\left(1-\theta \gamma_{f}-(1-\theta) \gamma_{m}\right)}\right)$, the first order condition of the maximization program:

$$
\frac{\left(\gamma_{f}+\gamma_{m}\right) \varepsilon}{(1+g)}-\frac{\left(1-\gamma_{f}\right)+\left(1-\gamma_{m}\right)}{(2 A-d)\left(1-\theta \gamma_{f}-(1-\theta) \gamma_{m}\right)-g}=0
$$

Effect of female bargaining power on fertility:

$$
\begin{array}{r}
\frac{\partial n(d, \theta)}{\partial \theta}=\chi\left(\gamma_{f}-\gamma_{m}\right)\left\{1+(2 A-d)\left[1-(1+\varepsilon)\left((1-\theta) \gamma_{m}+\theta \gamma_{f}\right)\right]\right\} \\
\text { with } \chi=\frac{(2 A-d)\left[\left(\gamma_{f}+\gamma_{m}\right) \varepsilon\right]^{\varepsilon}\left[1+(2 A-d)\left(1-\theta \gamma_{f}-(1-\theta) \gamma_{m}\right)\right]^{\varepsilon-1}}{(A-d) \phi\left[\left(\gamma_{f}+\gamma_{m}\right) \varepsilon+\left(1-\gamma_{f}\right)+\left(1-\gamma_{m}\right)\right]^{\varepsilon}}
\end{array}
$$

\section{F Gender discrimination effects}

$$
\begin{aligned}
& \frac{\partial\left(1-h_{f}(d, \theta(d))\right)}{\partial d}=\frac{\partial\left(1-h_{f}(d, \theta(d))\right)}{\partial d}+\frac{\partial\left(1-h_{f}(d, \theta(d))\right)}{\partial \theta} \quad \frac{\partial \theta(d)}{\partial d} \\
& (-) \quad(+) \text { if } \gamma_{m}>\gamma_{f} \quad(-) \\
& (-) \text { if } \gamma_{f}>\gamma_{m} \\
& \frac{\partial \tau(d, \theta(d))}{\partial d} \quad=\quad \frac{\partial \tau(d, \theta(d))}{\partial d} \quad+\quad \frac{\partial \tau(d, \theta(d))}{\partial \theta} \quad \frac{\partial \theta(d)}{\partial d} \\
& (-) \quad(+) \text { if } \gamma_{m}>\gamma_{f} \quad(-) \\
& \frac{\partial n(d, \theta(d))}{\partial d} \quad=\quad \frac{\partial n(d, \theta(d))}{\partial d}+\frac{\partial n(d, \theta(d))}{\partial \theta} \quad \frac{\partial \theta(d)}{\partial d} \\
& (-) \text { or }(+) \quad(-) \text { or }(+) \quad(-)
\end{aligned}
$$




\section{References}

Adserà, A. (2004). Changing fertility rates in developed countries. the impact of labor market institutions. Journal of Population Economics 17, 17-43.

Aguiar, M. and E. Hurst (2007). Measuring trends in leisure: The allocation of time over five decades. The Quarterly Journal of Economics, 969-1006.

Ahn, N. and P. Mira (2002). A note on the changing relationship between fertility and female employment rates in developed countries. Journal of Population Economics 15, $667-682$.

Aigner, D. J. and G. G. Cain (1977). Statistical theories of discrimination in labor market. Industrial and Labor relations review 30(2), 175-187.

Alesina, A., A. Ichino, and L. Karabarbounis (2007). Gender based taxation and the division of family chores. NBER Working paper No. 13638.

Altonji, J. G. and R. M. Blank (1999). Race and Gender In the Labor Market (Ashenfelter, C. and Card, D. ed.), Volume 3C, Amsterdam: North-Holland.

Apps, P. F. and R. Rees (1997). Collective labor supply and household production. Journal of Political Economy 105(1), 178-190.

Apps, P. F. and R. Rees (2004). Fertility, female labor supply and public policy. Scandinavian Journal of Economics 106, 745-763.

Becker, G. (1957 (1971)). The Economics of Discrimination (1 (2nd) ed.). University of Chicago Press.

Bettio, F. and P. Villa (1998). A mediterranean perspective on the breakdown of the relationship between participation and fertility. Cambridge Journal of Economics 22, $137-171$.

Bourguignon, F. and P.-A. Chiappori (1992). Collective models of household behavior. European Economic Review 36, 355-364.

Brewster, K. L. and R. R. Rindfuss (2000). Fertility and women's employment in industrialized nations. Annual Review of Sociology 26, 271-296.

Burda, M., D. S. Hamermesh, and P. Weil (2007). Total work, gender and social norms. IZA Discussion paper No.2705.

Cavalcanti, T. and J. Tavares (2007). Women prefer larger governments: Growth, structural transformation and government size. Working paper.

Chesnais, J.-C. (1996). Fertility,family, and social policy in contemporary western europe. Population and Development Review 22(4), 729-739. 
Chiappori, P.-A. (1997). Introducing household production in collective models of labor supply. The Journal of Political Economy 105(1), 191-209.

Chichilnisky, G. and E. Hermann Frederisken (2008). An equilibrium analysis of the gender wage gap. International Labour Review 147(4), 297-320.

Coate, S. and G. Loury (1993). Will affirmative-action policies eliminate negative stereotypes? The American Economic Review 83(5), 1220-1240.

D'Addio, A. C. and M. Mira d'Ercole (2005). Politiques, institutions et taux de fécondité : Une analyse sur données de panel appliquée aux pays de l'ocde. Revue économique de l'OCDE 2(41).

Del Boca, D. and M. Locatelli (2007). Social Policies, Labour Markets and Motherhood (Del Boca, D. and Wetzels, C. ed.)., Chapter 5 Motherhood and participation, pp. 155-181. Cambridge University Press.

European commission, E. U. (2004). Employment in europe.

Fagnani, J. (2002). Why do french women have more children than german women? family policies and attitudes towards childcare outside the home. Community, Work and Family 5(1), 103-119.

Fernandez, C. and A. Sevilla-Sanz (2006). Social norms and household time allocation. IESE Working Paper No.645.

Fernandez, R., A. Fogli, and C. Olivetti (2004). Mothers and sons : Preference formation and female labor force dynamics. The Quarterly Journal of Economics.

Francois, P. (1998). Gender discrimination without gender difference: Theory and policy responses. Journal of Public Economics 68, 1-32.

Freeman, R. B. and R. Schettkat (2005). Marketization of household production and the eu-us gap in work. Economic Policy.

Galor, O. and D. N. Weil (1996). The gender gap, fertility and growth. American Economic Review 86(3), 374-387.

Gauthier, A. H. (2002). Les politiques familiales dans les pays industrialisés: y a-t-il convergence? Population(French Edition) (3), 457-484.

Hantrais, L. (1997). Exploring relationship between social policy and changing family forms within the european union. European Journal of Population 13, 339-379.

Hausmann, R., L. D. Tyson, and S. Zahidi (2009). The global gender gap report. Technical report, World Economic Forum, Geneva, Switzerland. 
Havet, N. (2004). Écarts salariaux et disparités professionnelles entre sexes : développements théoriques et validité empirique. L'Actualité économique 80(1), 5-39.

Hellerstein, J. K., D. Neumark, and K. R. Troske (1999). Wages, productivity, and worker characteristics: Evidence from plant-level production functions and wage equations. Journal of Labor Economics 17(3), 409-446.

Hellerstein, J. K., D. Neumark, and K. R. Troske (2002). Market forces and sex discrimination. The Journal of Human Resources XXXVII, 353-380.

Jaumotte, F. (2003). Les femmes sur le marché du travail : Evidence empirique sur le rôle des politiques économiques et autres déterminants dans les pays de l'ocde. Revue économique de l'OCDE (37).

Lindbeck, A. and J. W. Weibull (1987). Balanced-budget redistribution as the outcome of political competition. Public Choice 52, 273-297.

Meurs, D. and S. Ponthieux (2005). The gender wage gap in europe : women, men and the public sector. Working Paper INSEE.

OECD (2002). Employment outlook. Technical report.

Pailhé, A. and A. Solaz (2008). Time with children: Do fathers and mothers replace each other when one parent is unemployed? European Journal of Population 24(2), 211-236.

Persson, T. and G. Tabellini (2000). Political Economics: Explaining Economic Policy. MIT Press.

Rizavi, S. S. and C. Sofer (2009). The division of labour within the household: Is there any escape from traditional gender roles? Working Paper.

The Economist, T. E. (2007). Womenomics revisited. Economic focus.

United Nations, U. N. (2002). Human development report. Technical report, The United Nations Development Programme. 